\title{
Military Surveillance System using IOT
}

\author{
Kirubakaran L. \\ UG Student \\ Department of Electronics \\ and Communication \\ Agni College of \\ Technology \\ Chennai, India
}

\author{
Sangeetha G. \\ UG Student \\ Department of Electronics \\ and Communication \\ Agni College of \\ Technology \\ Chennai, India
}

\author{
Rathna Priya S. \\ UG Student \\ Department of Electronics \\ and Communication \\ Agni College of \\ Technology \\ Chennai, India
}

\author{
Sudharsan S. \\ Assistant Professor \\ Department of Electronics \\ and Communication \\ Agni College of \\ Technology \\ Chennai, India
}

\begin{abstract}
This project provides better surveillance for our country by using Internet of things. It is a Rover type device which is useful in high risky boundary regions and the lands where human cannot enter. In this project, the motion of the rover and the rotation of the camera can be controlled using internet. Therefore, we can control this device from anywhere in the world. It provides live streaming and more information about that area. Active IR sensor is used for obstacle detection for safe motion of the rover. It also has MQ2 smoke sensor which senses the inflammable gas and the gas presence in the environment. Ultrasonic sensor is used to detect the motion of the objects present in the surroundings. In this project camera can controlled by using pan and tilt servo motors. Land Mines can also be detected by using Land mine detection circuit. IOT is easily supported using Raspberry pi 3 model B. SD card is used for storing the sensed information. This device is used to prevent the human casualty and abnormal hazardous events. It prevents forest fire with help of smoke sensor. This device can also be useful for detecting and surveillance purposes. GPS is used to find the current location of rover in the map.
\end{abstract}

\section{Keywords}

Raspberry-Pi, IOT, Smoke sensor, Ultrasonic sensor, Active IR sensor, Land Mine detection, pan-tilt camera, GPS.

\section{INTRODUCTION}

In this modern world drones, CCTV, RADAR and man power is used for surveillance purposes. India has 15,106 kilometres of land borders which is being shared among 7 countries such as China, Pakistan, Bhutan, Myanmar, Afghanistan, Nepal and Bangladesh. India's coastal border is protected by the Border Security Force. Multiple soldiers and guards protect our country but still lot of issues is faced due to various factors such as weather, environment and health of human. So it is mandatory to use a device that senses the environment and send information to make sure that the country is protected. Also, a land mine buried under the ground does not differentiate between soldier and a civilian which results in killing and injuring people and remains active for about 50 years. Thus the people living near the International border and Line of control are in a state of high vulnerability. Detecting mines in dense forest and human risky regions are difficult. So it could be a good initiative to provide better surveillance to reduce human mobility. In addition, it is necessary to detect the mines before stepping on it.

\section{EXISTING SYSTEM}

For the purpose of surveillance, various methods have been deployed. These include CCTV cameras, drones, etc. Drones are manned or unmanned vehicles capable of flying over a particular region either manually or automatically piloted by computers. This provides information only up to a certain distance from ground. This method fails on certain conditions such as downpour, derecho, etc. Considering the security of the nation, laser fencing is built across borders to prevent the entry of strangers. This method fails as it cannot be built everywhere around the border. CCTV's also cannot be fixed everywhere for monitoring purpose. For different application, separate modules are used. This increases the number of modules to be used. The existing system has its own disadvantages which are eliminated in the proposed system.

\section{PROPOSED SYSTEM}

Rover type device is used for surveillance purpose where humans cannot enter and high risky boundary regions. It has various modules such as camera, sensors, land mine detector circuit to obtain the information about the region under surveillance. Camera can be controlled by the user by giving directions through web browser with the help of pan and tilt servo motors. This provides $24 * 7$ live surveillance and it can be stored in storage device. Rover has the following sensors namely active infrared sensor, MQ2 gas sensor and ultrasonic sensor. Active IR sensor is used to identify the obstacles nearer to the device. Grove - Gas Sensor (MQ2) is used for detection of gas leakage such as alcohol, smoke, hydrogen, methane, propane, LPG as well as carbon monoxide. This device will provide information about the forest fire, leakage of gases, smoke and determines the quality of air in the region. Ultrasonic sensor is used to identify the motion of the human or the target object in that environment by measuring the distance using ultrasonic waves. Land mine detection circuit is used to detect the mines buried underground preferably metals. This device is used for spying the regions by controlling the motion directions from anywhere in the world through web server. The main objective of this project to avert human mobility and provide better surveillance.

\section{HARDWARE AND SOFTWARE DESCRIPTION}

In the proposed system, 20000mAh lithium Polymer battery is used to store maximum electrical energy and provide that stored electrical power to charge up the pi board. This can lasts for10 hour per day. 


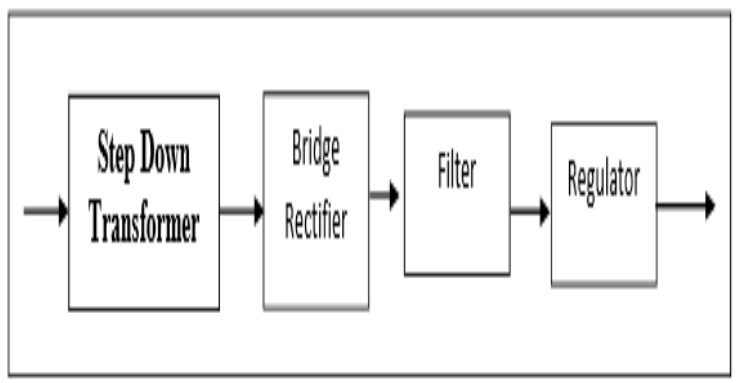

Figure 1: Block Diagram of Linear Power Supply

Motor Driver L293D is used to control DC motors. It requires separate power supply because it operates at high current and low voltage hence the circuit operation is protected from it by using separate battery supply.

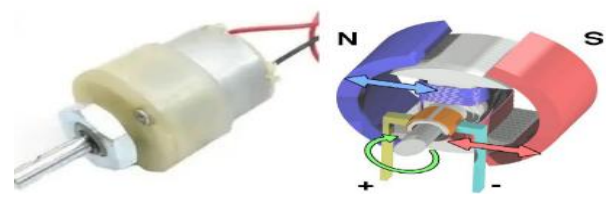

Figure 2: DC Motor

Pi Camera usually placed on the external body of a vehicle and provide real-time video for the driver of anything which is happening outside. This provides 3 main application: raspi still, raspi vid and rapistillyuv. Both raspi still and raspistillyuv are too smaller which are used for capturing images, while raspi vid is mainly used for capturing video.



Figure 3: Raspberry pi camera

Ultrasonic sensor is used for Robot navigation, Obstacle avoidance, engineering measurement tools in this system. This sensor emits ultrasonic waves and measures the time till it returns back after reflection from the object that got hit. The sensor has two pins namely trig and echo which is connected to the controller to provide digital input and digital output. The distance between the rover and the target object is calculated which is then sent to the user, who has the full control of the rover.

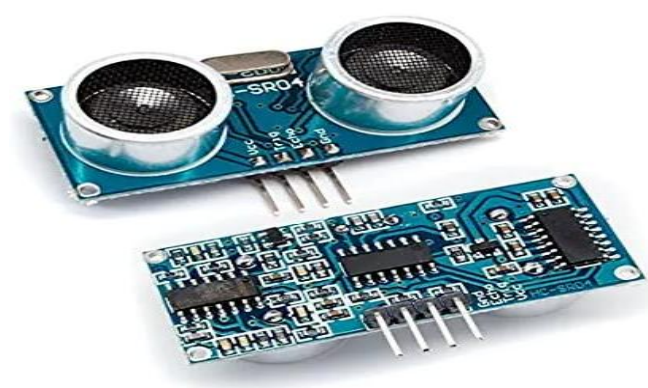

Figure 4: Ultrasonic sensor
Grove - Gas Sensor (MQ2) is used for detection of gas leakage such as alcohol, smoke, hydrogen, methane, propane, LPG as well as carbon monoxide. This sensor is highly sensitivity to methane, smoke and oxygen. Thus provides information about the forest fire, leakage of gases, smoke and determines the quality of air in the region. This alerts the user when there is a presence of smoke or other gases.

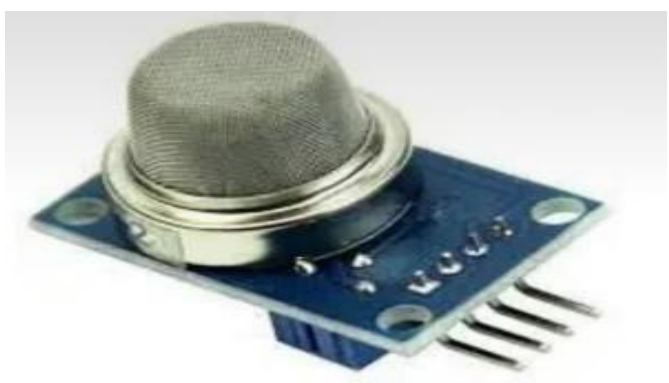

Figure 5: MQ2 Smoke sensor

Metal detectors are useful for finding metal inclusions hidden within objects or metal objects buried upto 10 to $15 \mathrm{~cm}$ from the ground surface. It uses electric current to create electromagnetic waves which is used to detect a metal on the ground. This circuit is simply a Colpitts's oscillator working in the medium band frequency and a radio tuned to the same frequency.

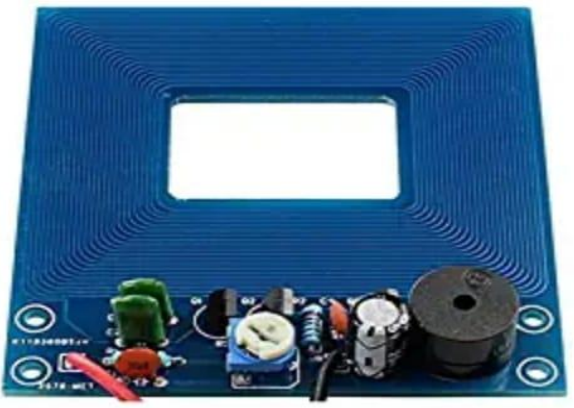

Figure 6: Metal detection sensor

Pan tilt module is ideal for a mini CCTV system, which pans and tilts through 180 degree in each axis. This set of horizontal and vertical motion servos will gives Pi camera movement with a minimum of fuss. This independently drives the two servos (Pan and tilt), which resembles as the eyes of the rover.

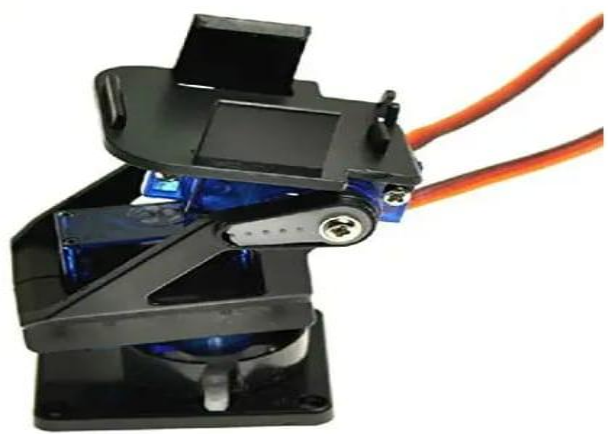

Figure 7: Pan Tilt Module

The NEO-6MV2 is a GPS (Global Positioning System) module, which is used for navigation and checks its location 
by providing the longitude and latitude of its position on the earth.

By using latitude and longitude values we can find the current location of rover in the maps. Global Positioning Service Component has a receiver pin which will receive the data from the satellite using antenna.

The compact architecture, power and memory options make NEO-6 modules ideal for battery operated mobile devices with very strict cost and space constraints. Its Innovative design gives NEO-6MV2 excellent navigation performance even in the most challenging environments.

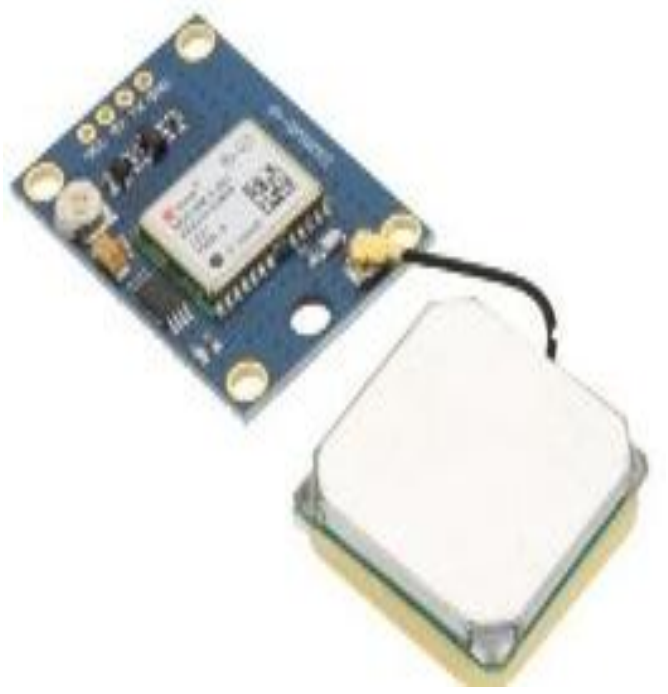

Figure 8: GPS Module

Raspberry Pi model $3 \mathrm{~B}$ is the core of this system. It has a Quad-Core 64 bit CPU, Wifi \& Bluetooth. It is a $3^{\text {rd }}$ generation Raspberry pi. The powerful credit card sized single board computer can be used for IOT based applications.

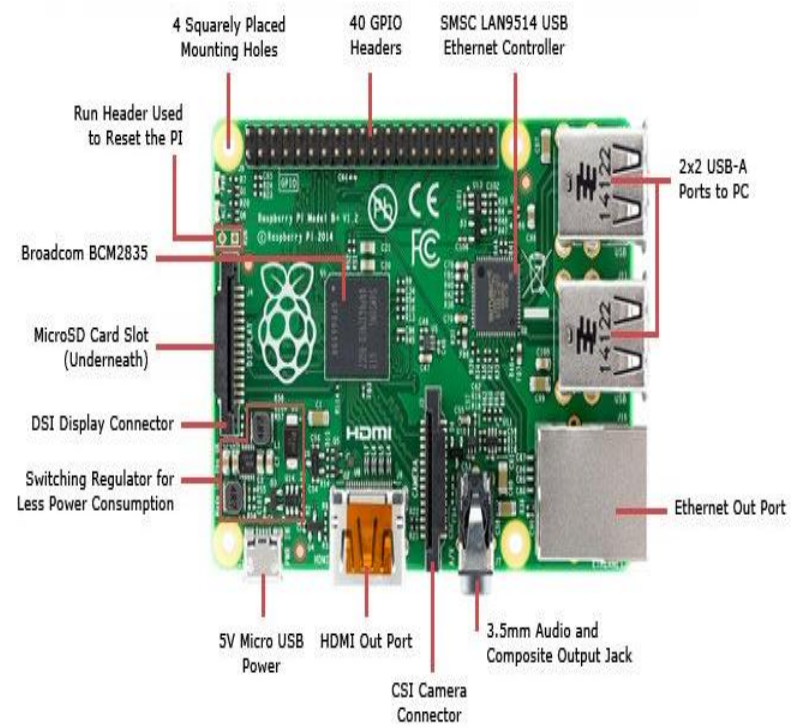

\section{WORKING FUNCTION}

In the transmitter section, the rover sends the data to the user, who controls the motion and camera rotation of the system. Also, when ultrasonic sensor detects a distance less than a specific length, then the rover alerts the user as well as the mine detector detects metallic or any other unknown objects immediately it will sends the information through IOT.GPS will sends the exact latitude and longitude position of rover.

In the receiving section, the user can monitor a particular area by live streaming and receives the sensed information from sensors through IOT. It gives information to determine forest fire, land mines, stranger intrusion and abnormal activities in that area. It is also very useful for spying purpose by controlling the motion of the rover using web servers

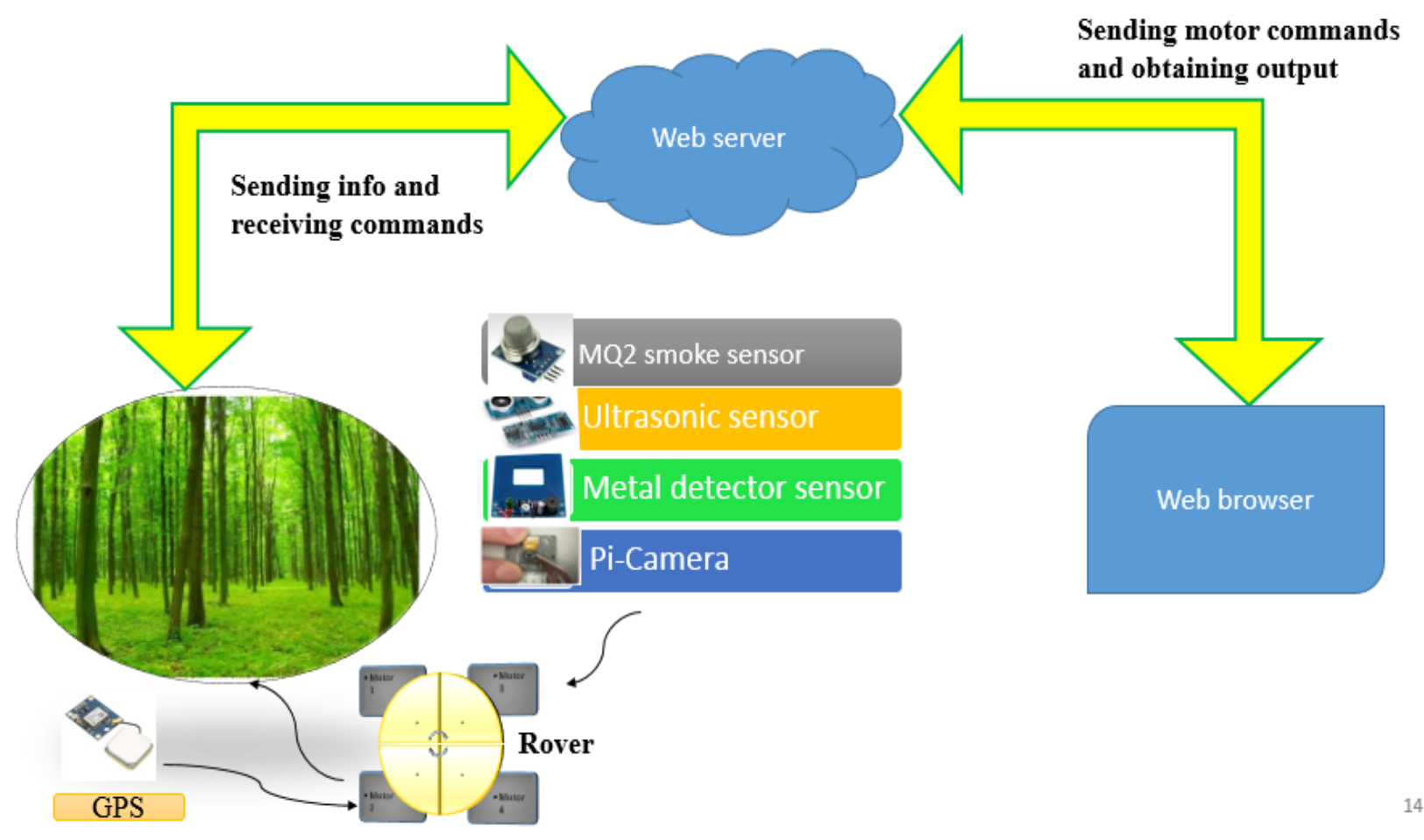

Figure 9: working function diagram 


\section{SIMULATION OUTPUT}

Motor forward condition

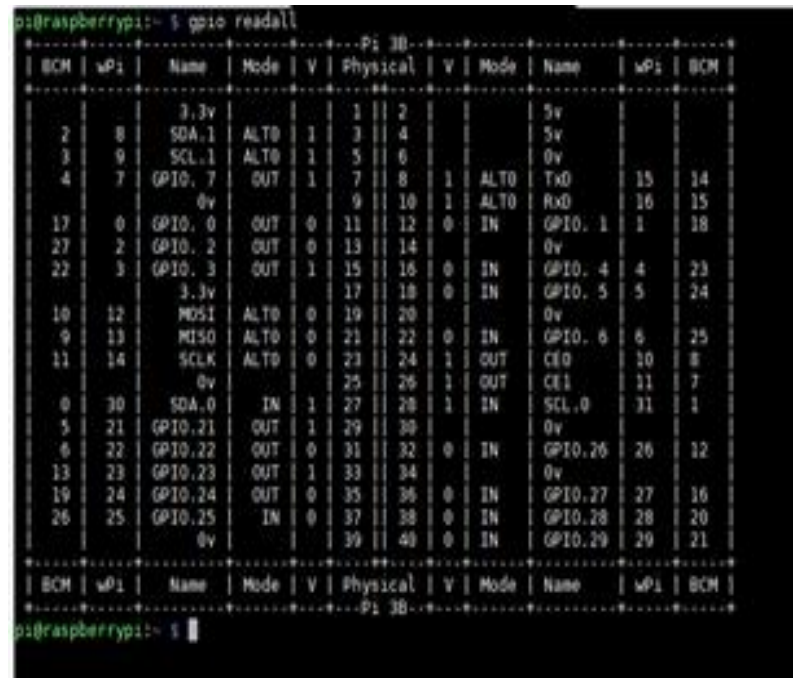

\section{Motor reverse condition}

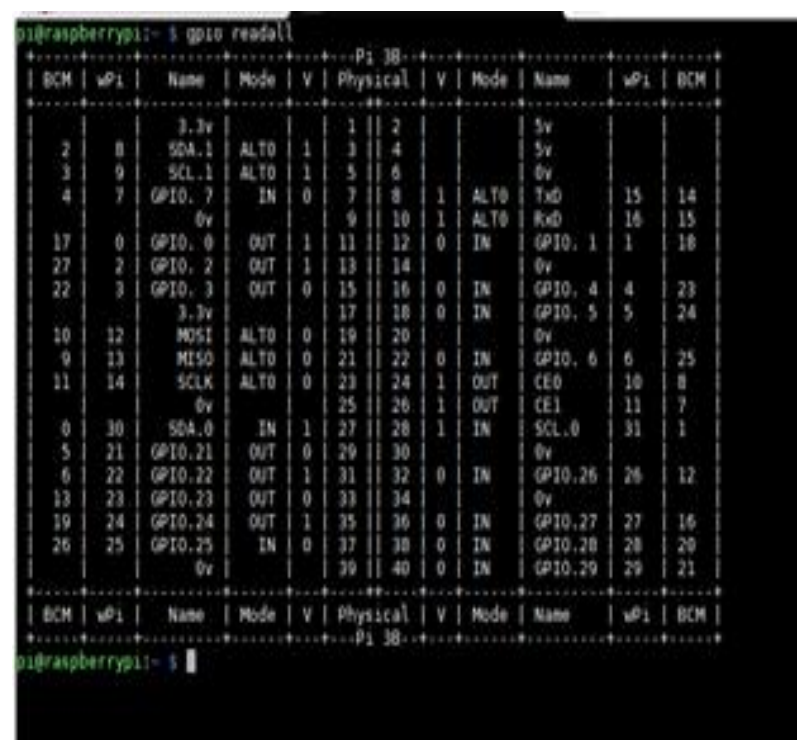

\section{Motor left condition}

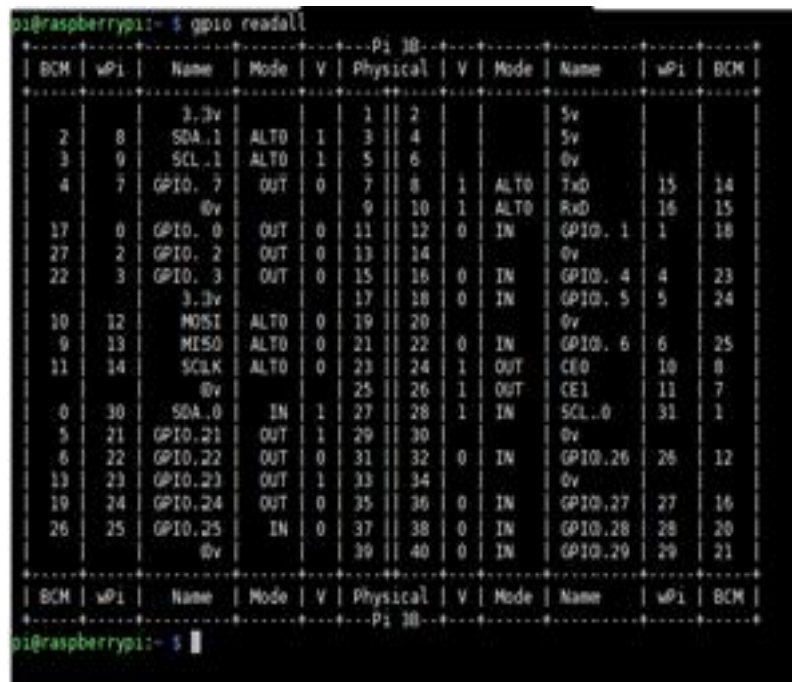

\section{Motor right condition}

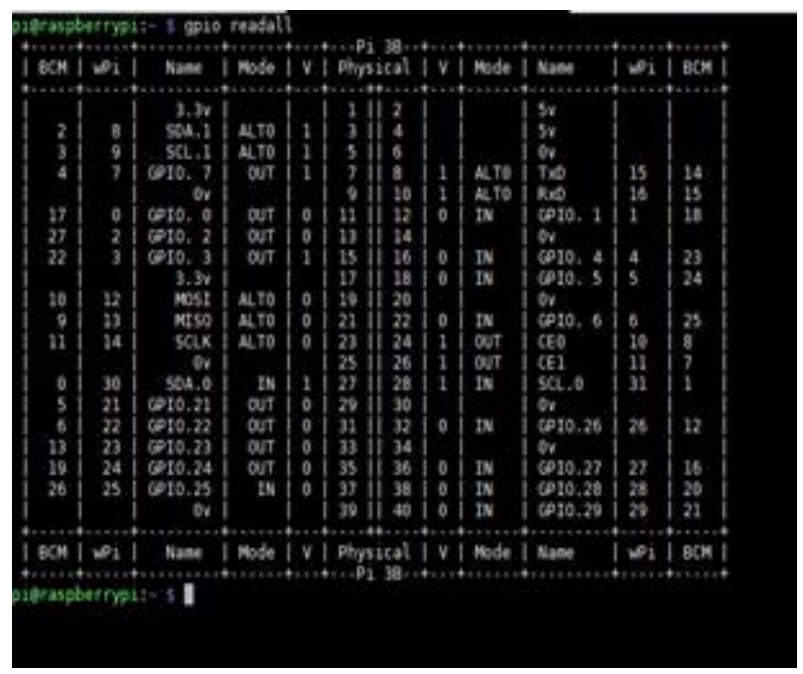

The above figures show the simulation output of the motor operations of the rover based on the commands given through internet using web browser by the user to the rover. The motor pins are connected to General Purpose Input Output pins of the Raspberry Pi microprocessor.

\section{Attached components Output:}

\section{Gps simulation output}

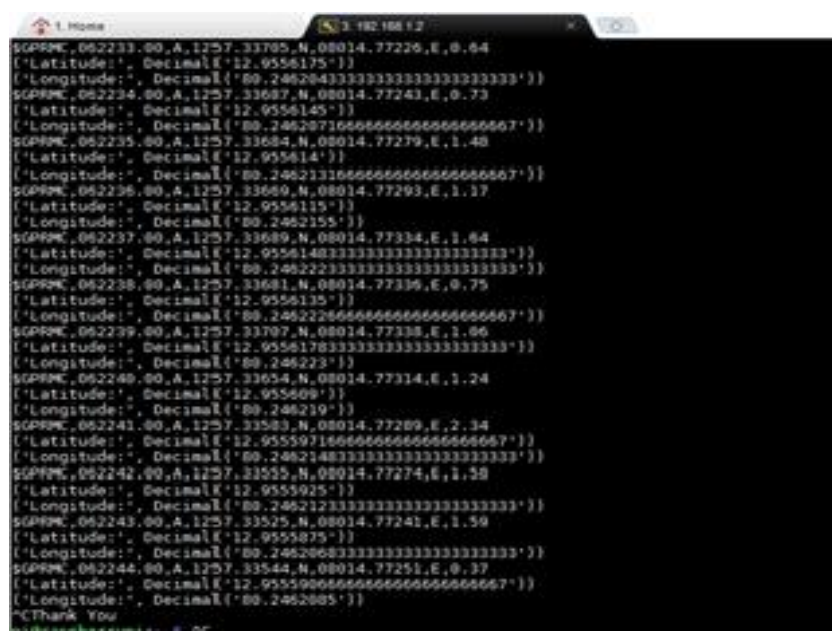

\section{Ultrasonic output}

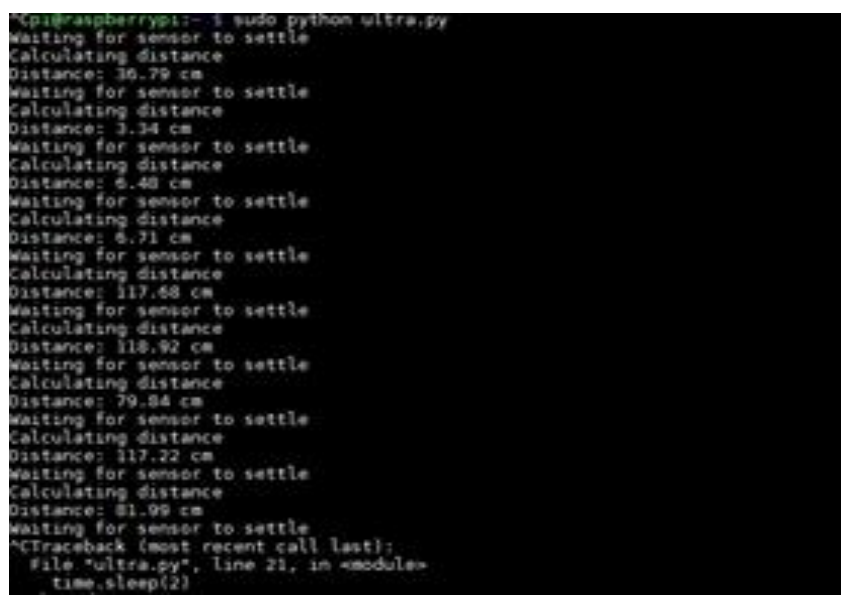




\section{Metal detector output}

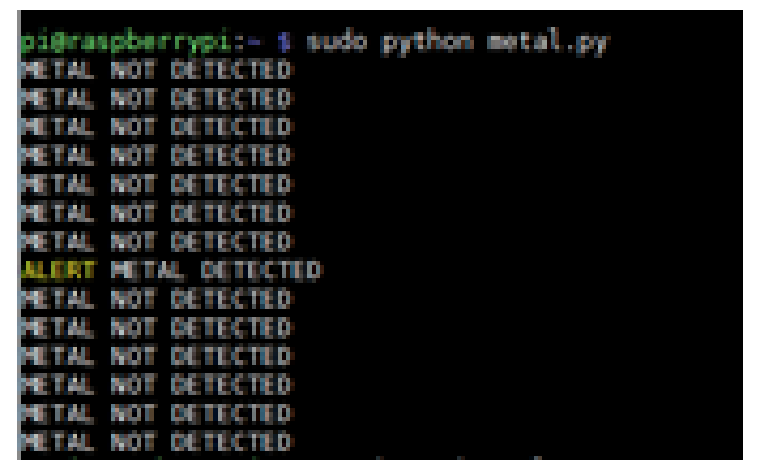

Above figures show the simulation output for individual process of the components which integrated on the rover and connected with Raspberry Pi model 3B pins.

\section{HARDWARE OUTPUT}

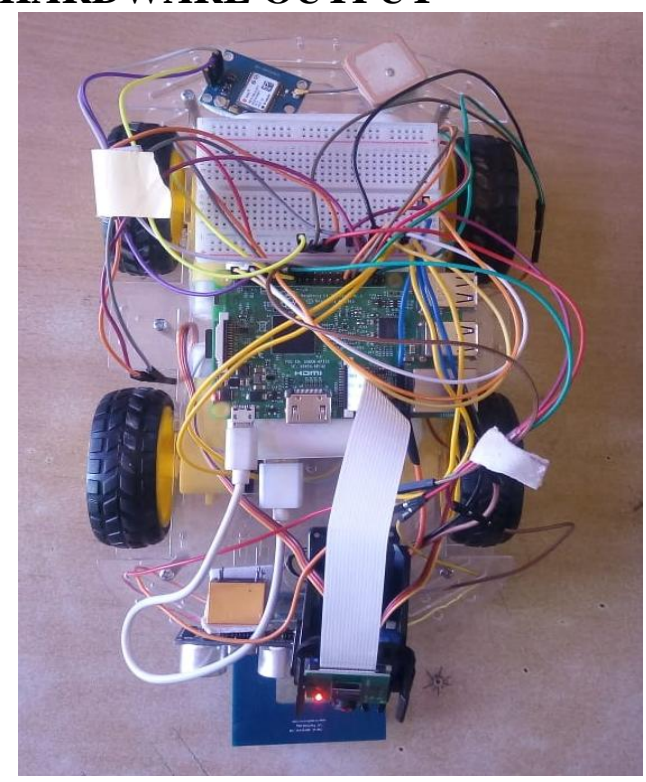

Figure 10. Surveillance rover

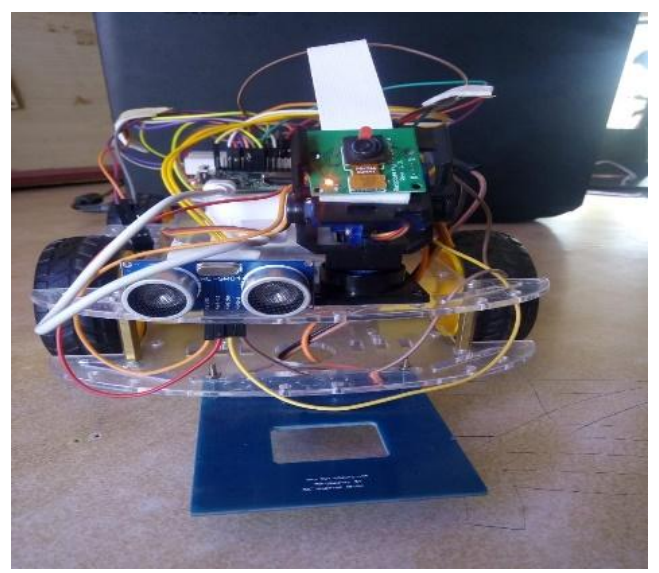

Figure 11. rover front view

\section{WEBPAGE LINK}

http://pirobo.pagekite.me/cam

From the above webpage link all the sensors output and camera streaming is available when the rover is connected with internet as well as user can control the motion and camera's rotation through it.

\section{CONCLUSION}

Rover based system for surveillance can be a good initiative for monitoring and protecting our country from enemy troops. This will be useful for better surveillance to reduce causalities. There are many soldiers and guards are protecting our country but still we are facing lot of issues due to weather, environment and health of human. So it is mandatory to use a device that senses the environment and send information to make sure the country is protected. This project can also be useful to better surveillance in home, industries, schools and work places. It will give a peaceful and healthy environment for our future generations.

\section{FUTURE SCOPE}

This project can be improved by integrating face recognition to understand the known person of the environment and renewable energy can be used as a power supply by some changes in the internal circuit of the power bank. Rover path can be traced using database to set destination using internet.

\section{REFERENCES}

[1] Chaitrali Jadhab, Shamli Gibile, Snehal Gaikwad, Neelum Dave, "Military spying and bomb disposal robot using IOT", International research journal of engineering and technology E-ISSN:2395-0056, P-ISSN:2395-0072, volume-5, Issue-4 April2018.

[2] D.N.S Ravi Kumar, Durgesh Kumar, "VNC server based robot form military applications", IEEE conference on power, control, signals and instrumentation engineering2017.

[3] Jignesh Patoliya, Haard Mehta, Hitesh Patel, "Arduino controlledWarfield spying robot using night vision wireless camera and android application", IEEE 5th Nirma University International Conference on Engineering 2015.

[4] Sarmad Hameed, Muhammad Hamza Khan, Naqi Jafri, Adeel Azfar Khan, Muhammad Bilal Taak, "Military spying robot", International Journal of Innovative Technology and Exploring Engineering ISSN:22783075, volume-8, Issue-7C2, May2019.

[5] Majd Ghareeb, Ali Bazzi, Mohammad Raad, Samih AbdulNabi, "Wireless Robo-Pi for LandMines detection". IEEE conference on Computer Science Engineering 2017.

[6] Prof. S. A Joshi, Aparna Tondarkar, Krishna Solanke, Rohit Jagtap , "Surveillance Robot for Military Application", International Journal Of Engineering And Computer Science ISSN:2319-7242 Volume 7 Issue 5 May 2018 